\title{
Observational Quantification of Climatic and Human Influences on Vegetation Greening in China
}

\author{
Wenjian Hua ${ }^{1,2,3, *}$, Haishan Chen ${ }^{1}$, Liming Zhou ${ }^{3}$, Zhenghui Xie ${ }^{2}$, Minhua Qin ${ }^{1}$, Xing Li ${ }^{1}$, \\ Hedi Ma ${ }^{1}$, Qinghan Huang ${ }^{1}$ and Shanlei Sun ${ }^{1}$ \\ 1 Key Laboratory of Meteorological Disaster, Ministry of Education (KLME)/Joint International Research \\ Laboratory of Climate and Environment Change (ILCEC)/Collaborative Innovation Center on Forecast and \\ Evaluation of Meteorological Disasters (CIC-FEMD), Nanjing University of Information Science and \\ Technology, Nanjing 210044, China; haishan@nuist.edu.cn (H.C.); qinminhua@gmail.com (M.Q.); \\ lixing@nuist.edu.cn (X.L.); mahedi@nuist.edu.cn (H.M.); qinghan.huang@gmail.com (Q.H.); \\ ppsunsanlei@126.com (S.S.) \\ 2 State Key Laboratory of Numerical Modeling for Atmospheric Sciences and Geophysical Fluid Dynamics, \\ Institute of Atmospheric Physics, Chinese Academy of Sciences, Beijing 100029, China; zxie@lasg.iap.ac.cn \\ 3 Department of Atmospheric and Environmental Sciences, University at Albany, State University of New \\ York, Albany, NY 12222, USA; lzhou@albany.edu \\ * Correspondence: wenjian@nuist.edu.cn; Tel.: +86-25-5873-1578
}

Academic Editors: Sangram Ganguly and Prasad S. Thenkabail

Received: 21 March 2017; Accepted: 27 April 2017; Published: 30 April 2017

\begin{abstract}
This study attempts to quantify the relative contributions of vegetation greening in China due to climatic and human influences from multiple observational datasets. Satellite measured vegetation greenness, Normalized Difference Vegetation Index (NDVI), and relevant climate, land cover, and socioeconomic data since 1982 are analyzed using a multiple linear regression (MLR) method. A statistically significant positive trend of average growing-season (April-October) NDVI is found over more than $34 \%$ of the vegetated areas, mainly in North China, while significant decreases in NDVI are only seen in less than $5 \%$ of the areas. The relationships between vegetation and climate (temperature, precipitation, and radiation) vary by geographical location and vegetation type. We estimate the NDVI changes in association with the non-climatic effects by removing the climatic effects from the original NDVI time series using the MLR analysis. Our results indicate that land use change is the dominant factor driving the long-term changes in vegetation greenness. The significant greening in North China is due to the increase in crops, grasslands, and forests. The socioeconomic datasets provide consistent and supportive results for the non-climatic effects at the provincial level that afforestation and reduced fire events generally have a major contribution. This study provides a basis for quantifying the non-climatic effects due to possible human influences on the vegetation greening in China.
\end{abstract}

Keywords: vegetation greenness; NDVI; human influences; China

\section{Introduction}

The past few decades have been characterized by a widespread increase in the greenness of northern forests [1-3]. An increase in vegetation greenness generally implies higher absorption of photosynthetically active radiation, and greater fractions of leaves and biomass [4]. These changes in land surface, especially over the Northern mid- and high-latitudes, may alter land surface properties such as albedo and aerodynamic roughness, influence the surface energy budget via partitioning between sensible and latent heat fluxes, and have important climatic implications [5-9].

Vegetation activities are largely influenced by climate change $[1,4,10]$ and many studies have linked spatiotemporal changes in vegetation to climate variations [2,11-14]. In general, vegetation 
growth primarily depends on three climate factors: temperature, precipitation, and radiation $[7,15]$. Nemani et al. [10] estimated that water mainly limits vegetation growth on over $40 \%$ of the Earth's vegetated surface, whereas temperature and radiation limit $33 \%$ and $27 \%$ of that growth, respectively. Regarding geographic patterns, precipitation matters most in arid and semi-arid areas, whereas radiation plays a dominant role in rainforests. The impact of temperature on vegetation growth is significant in the northern high latitudes. For example, climate warming generally leads to an increase in growing season length and enhanced photosynthesis in temperature-limited regions $[1,2,16]$. However, de Jong et al. [17] noted that the climate is only able to explain approximately $54 \%$ of the variations in vegetation activity over the past few decades, while human activities (e.g., land use change, LUC) may also have a contribution [18-20]. Thus, quantifying vegetation dynamics such as vegetation greening and browning and understanding the driving mechanisms behind these variations are long-standing scientific issues in the climate change research community.

Evidently both climate change and human activities are the main driving forces of variations in terrestrial ecosystems, but it is difficult to directly differentiate these two factors. Recently, Piao et al. [21] first detected and attributed the trends in vegetation (Leaf Area Index, LAI) greening at global scales using different ecosystem models. Besides rising atmospheric $\mathrm{CO}_{2}$ concentrations and nitrogen deposition, climate change and LUC are the main drivers for the vegetation trends. Zhu et al. [22] used ten global ecosystem models to investigate the main drivers of LAI trends in recent decades and found that climate change results in the greening of the high latitudes and the Tibetan Plateau, whereas LUC explains most of the regional greening trends in China and the United States. However, the climatic responses of vegetation remain uncertain because vegetation-climate relationships vary spatiotemporally and there are other limitations as well [23]. Therefore, it is imperative to isolate the effects of climate change and anthropogenic activities on the observed vegetation greening/browning.

China has the largest planted forest area in the world, approximately 69.3 million hectares [24], and the Chinese government has launched several ecological rehabilitation and conservation programs since the late 1990s, such as the Natural Forest Protection Program and the Three-North Shelter Forest Program [25]. Analyzing satellite measurements of the Normalized Difference Vegetation Index (NDVI) showed a pronounced greening trend in China since 1982 [26-28]. A thorough assessment of the relative contribution of climatic and non-climatic effects on the observed greening is necessary. Ecosystem modelling studies suggested that LUC is a dominant driver of the greening in China, especially in southeastern areas [21,22]. However, such studies often compare simulated LAI, which has uncertainties due to model deficiencies [29,30], against satellite derived LAI, which is a retrieved variable through the inversion of radiative transfer models and thus contains additional uncertainties in the input data, model imperfections, and the inversion process [31]. Therefore, further investigation using various observations and different approaches will help to validate the modeling results and provide complementary information about the greening.

The availability of multiple observational datasets (e.g., satellites-based vegetation, land cover, and socioeconomic data) provides us with a unique opportunity to identify different human-induced factors on the observed greening and distinguish their roles from climate effects. The present study attempts to quantify the relative contributions of vegetation greening trends in China due to climatic and human influences from several observational datasets. We analyze the widely-used third generation Normalized Difference Vegetation Index (NDVI3g) dataset generated from the Advanced Very High Resolution Radiometer (AVHRR). Satellite-based vegetation indices such as NDVI are direct optical measures of canopy greenness, and are highly correlated with leaf chlorophyll content, leaf area, canopy cover, and structure [1]. 


\section{Materials and Methods}

\subsection{Data Sets}

The third generation NDVI datasets (NDVI3g) generated from AVHRR sensors by the Global Inventory Monitoring and Modeling Studies (GIMMS) are used for the analysis [32,33]. The NDVI3g datasets have 1/12 degree spatial resolution and 15-day temporal frequency starting from July 1981 to 2012. It was corrected to minimize several non-vegetation signals due to calibration loss, orbit drift, and volcanic eruptions, and has been widely used in previous studies [14,34,35].

We use the International Geosphere-Biosphere Programme (IGBP) DISCover and SiB Land Cover product from the International Satellite Land-Surface Climatology Project, Initiative II (ISLSCP II). This data (hereinafter referred to as LU1992) is a land cover map with 1 kilometer resolution using a full year of AVHRR data (April 1992-March 1993) [36]. The globally validated Collection 5 MODerate resolution Imaging Spectroradiometer (MODIS) products of land cover and percentage vegetation cover (MCD12C1, 2001-2012) at $0.05^{\circ}$ spatial resolution are also used in this study [37].

The recently established gridded datasets (referred to CN05.1) based on observations from more than 2400 surface meteorological stations provide better support for high-resolution climate change research and model validation over the Chinese region [38]. Monthly mean air temperature and precipitation data at $0.25^{\circ}$ resolution are used. In addition, solar radiation data at a spatial resolution of $0.5^{\circ}$ are obtained from the CRU-NCEP v5.2 dataset (see [39,40], website: http://dods.extra.cea. $\mathrm{fr} /$ data/p529viov/cruncep). This dataset is derived from a combination of the CRU TS3.2 and the NCEP/NCAR reanalysis. All these datasets have been widely used in climate change studies [41,42].

Socioeconomic data at the provincial level from the China Statistical Yearbooks are collected to analyze the underlying non-climate factors that influence the changes in vegetation. Selected provincial-level socioeconomic variables include forest fires (1987-2012) and planted forest areas (1991-2012). To examine the effects of urbanization, we use the provincial-level built-up urban area data as well.

\subsection{Methodology}

We resample the biweekly NDVI data for the period from 1982-2012 to a common resolution grid $\left(0.25^{\circ} \times 0.25^{\circ}\right)$ to match the resolution of the climate data and further aggregate it to a monthly temporal resolution using the maximum value composite (MVC) method [43]. Growing season NDVI (simply referred to as NDVI hereafter) is defined as the average of NDVI from April to October each year, following Zhou et al. [1]. Pixels with the mean NDVI value $<0.1$ are masked as non-vegetated areas.

To assess the large-scale long-term NDVI trends, we use four different approaches (i.e., a linear trend estimate method, a composite analysis, a persistent index, and an Empirical Orthogonal Function (EOF) analysis) to quantify the NDVI trends. Despite its simplicity, the linear trend method based on least squares regression has been by far the most widely-used and effective approach to quantify NDVI trends in many previous studies. However, this method is very sensitive to outliers in the data used. First, to obtain consistent and more robust results, we use the Theil-Sen trend estimate method to calculate the observed NDVI trends [44], with the confidence intervals estimated using the Mann-Kendall test [45]. The Theil-Sen trend estimate is a robust estimate of linear trends. It is insensitive to outliers and significantly more accurate than simple linear regression, and competes well against non-robust least squares even for normally distributed data in terms of statistical power. The NDVI time series is deseasonalized prior to the trend estimation. Second, we simply use the last and first certain years to do the composite analysis to quantify the NDVI changes. Third, to illustrate the changes in NDVI, we further employ a persistence index following Zhou et al. [1], which can identify regions where the NDVI has consistently increased. For this method, NDVI trends for 8 periods, 1982-1991, 1982-1994, 1982-1997, . . , 1982-2012, denoted as trend (i), $\mathrm{i}=1,2,3, \ldots, 8$, are estimated. A score of 1 is given if the trend ( $i+1)>70 \%$ of trend (i); otherwise the score is 0 for period i. The sum of these scores is the persistence index, which ranges from 0 to 7 . In general, a persistence 
index of 4 or more is termed "high persistence", and "low persistence" refers to indexes less than 4. Fourth, we employ an EOF analysis to investigate spatially coherent patterns in the temporal variations of vegetation. EOF analysis has been extensively used to analyze the spatiotemporal variability of geophysical fields by decomposing the data into a set of spatial patterns of variability (referred to as EOF modes) and corresponding time variations (referred to as EOF time series). Its goal is to express the variability signal in terms of a relatively small number of EOFs to describe as much of the original information as possible. The EOF modes show the spatial structure of the major factors that can account for the temporal variations, which represents spatial variability. The EOF time series tells us how the amplitude of each EOF mode varies with time. The first few EOFs contain the majority of the data variance and the highest spatial coherence. The detailed descriptions of the methodology can be found in [46]. Note that short-term greening/browning variations associated with short-term climate disturbances (e.g., El Niño-Southern Oscillation (ENSO) events) and human factors (e.g., land use change) may cause large NDVI changes during the study period. However, our focus is on the large-scale long-term NDVI trends, not the short-term NDVI variability, and thus we use these four different approaches to quantify the NDVI trends and obtain consistent results.

We perform a multiple linear regression (MLR) analysis to separate the climatic and non-climatic factors driving the NDVI variations. Given the close linkage between NDVI and climate, we assume that the climatic effects on NDVI are primarily the result of variations in temperature, precipitation, and radiation (cloud cover) [10,47]. The NDVI variations associated with the climatic effects are estimated via the MLR analysis. The residual term in NDVI obtained by removing the climatic effects from the original NDVI data is assumed to represent the non-climatic effects due to human activities and other ecological disturbances. To address autocorrelations in the residuals, we employ a prewhitening procedure following Tung and Zhou [48] in the MLR analysis to satisfy the Durbin-Watson test to ensure that the residuals are whitened [49]. A two-tailed Student's $t$-test is then employed to measure the statistical significance level.

To attribute the non-climatic effects on NDVI variations, we use the changes in land cover between LU1992 and MCD12C1 in 2012 to quantify the long-term vegetation cover change (2012 versus 1992). These two land cover maps adopted the same land cover classification scheme which identified 17 classes defined by the IGBP, including 11 natural vegetation classes, 3 human-altered classes, and 3 non-vegetated classes. We use the land cover percentage information (i.e., the percentage of each pixel covered by each land cover type) to reproject the two maps into a common coarser resolution grid of $0.25^{\circ}$ by $0.25^{\circ}$, which tells us how much of a grid contains forests, croplands, grasslands, etc. Note that there are uncertainties and limitations at pixel levels due to the differences (e.g., data quality, acquisition times, sensors, and methods) in these two datasets [50], but the large-scale patterns in LUC should be of adequate quality [51-53] to provide potential information of the recent two decades for understanding and monitoring vegetation distribution and dynamics.

\section{Results}

\subsection{NDVI Changes}

We first examine the spatial distribution of the 31-year (1982-2012) mean NDVI over China (Figure 1). Overall, the NDVI increases from southeast to northwest and ranges from 0.4 to 0.6 over northern China, $<0.1$ in the Xinjiang Uygur Autonomous Region and west of the Inner Mongolia region, and $>0.7$ in Fujian, Zhejiang, south of Shanxi, and west of Hubei Province. We calculate the NDVI changes as the differences between the last eight years (2005-2012) and the first eight years (1982-1989) (Figure 2a). Substantial increases in NDVI occur especially in central China $\left(105^{\circ}-110^{\circ} \mathrm{E}\right.$ and $\left.30^{\circ}-40^{\circ} \mathrm{N}\right)$, North China $\left(105^{\circ}-120^{\circ} \mathrm{E}\right.$ and $\left.35^{\circ}-45^{\circ} \mathrm{N}\right)$, and Guangxi Province. We also define the composite periods differently such as the last and first 10 or 12 years and obtain similar results (not shown). The overall 31-year mean trend in the growing season NDVI at each grid point is shown in Figure $2 b$. In general, vegetation greenness has increased over the past few decades, and such 
increases are consistent with the NDVI changes illustrated in Figure 2a. Some areas, including the Xinjiang Uygur Autonomous Region, west of the Inner Mongolia region, and northeast China, show a decreasing trend. Based on the definition of the persistence index by Zhou et al. [1], a high persistency (larger than 4) has occurred over central China (Figure 2c). The regions of high persistence are located over the densely vegetated areas (which of course have high average growing season NDVI).
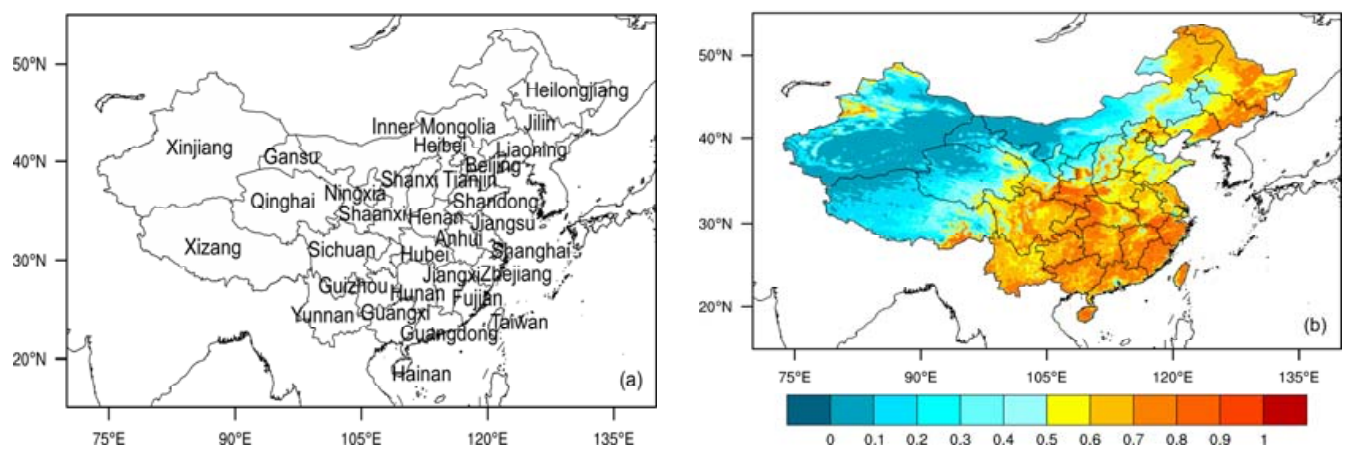

Figure 1. (a) The provincial administrative regions in China and (b) spatial patterns in the climatological Normalized Difference Vegetation Index (NDVI) averaged from 1982 to 2012.

The changes in NDVI that are estimated using the above three methods (Figure 2) consistently show that most areas in China have experienced a greening trend since 1982, and the regions with the largest greening trend $\left(>0.03\right.$ decade $\left.^{-1}\right)$ are generally located in southern China and in part of the North China Plain. From the frequency distribution of the significance level ( $p$ values) of the trends (Figure 3), it is found that the NDVI has significantly increased in more than $34 \%(19 \%)$ of the study regions at $p \leq 0.1(p \leq 0.01)$, whereas remarkable decreases are seen in less than $5 \%$ of the areas.
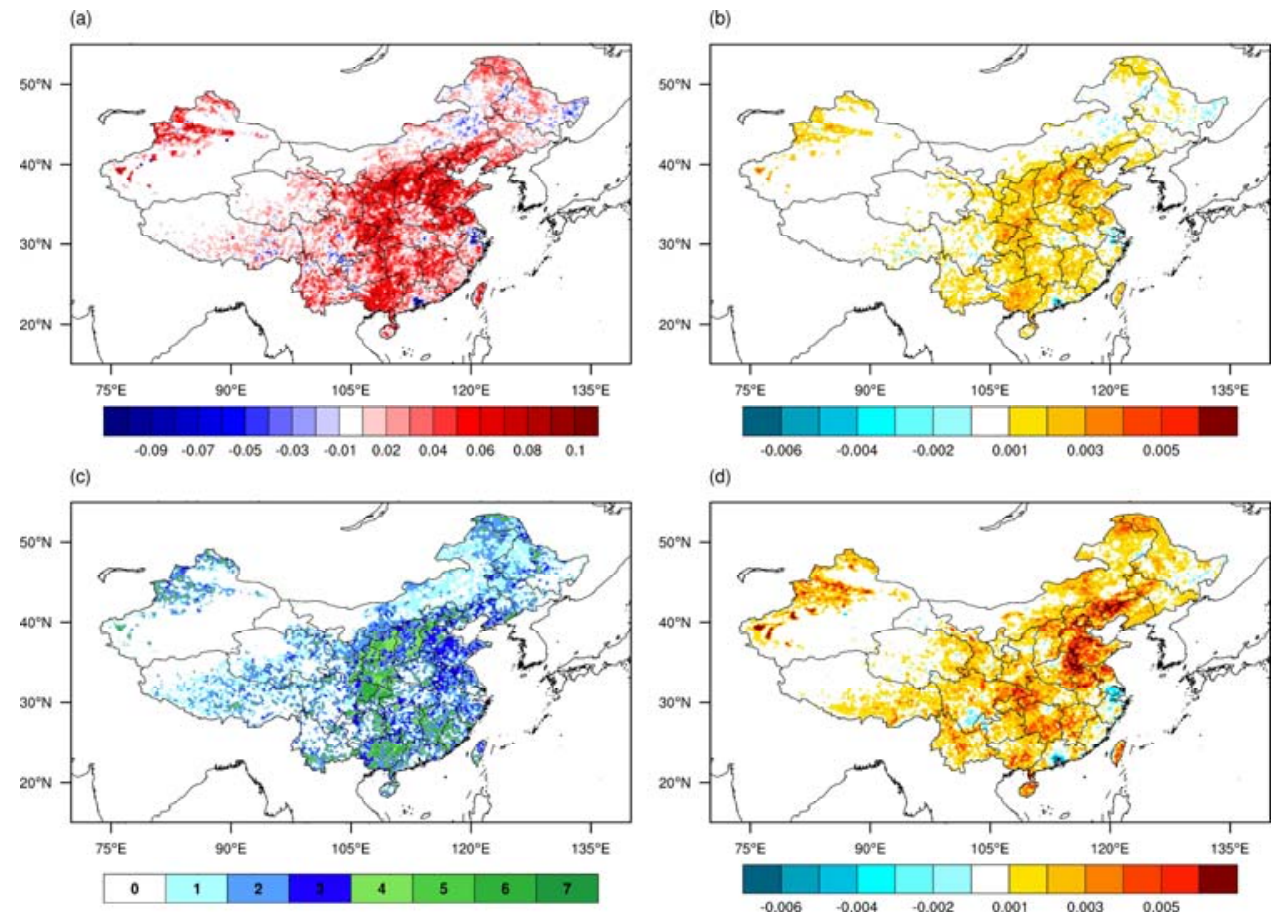

Figure 2. Spatial patterns in (a) NDVI differences between 2005-2012 and 1982-1989; (b) NDVI trends from 1982 to 2012; and (c) the persistence index in increases in NDVI, during the growing season for the period from 1982-2012; and (d) the trend in NDVI $(p<0.01)$ from 1982 to 1999. 


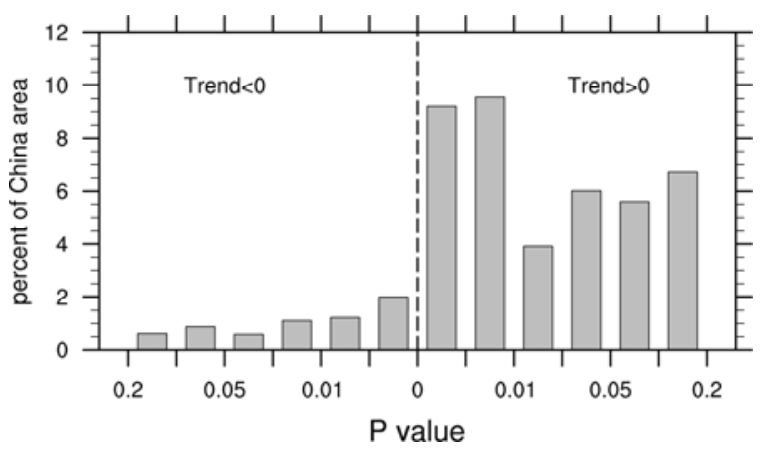

Figure 3. Histograms of NDVI trends shown in Figure $2 \mathrm{~b}$ as a function of $p$ values in China.
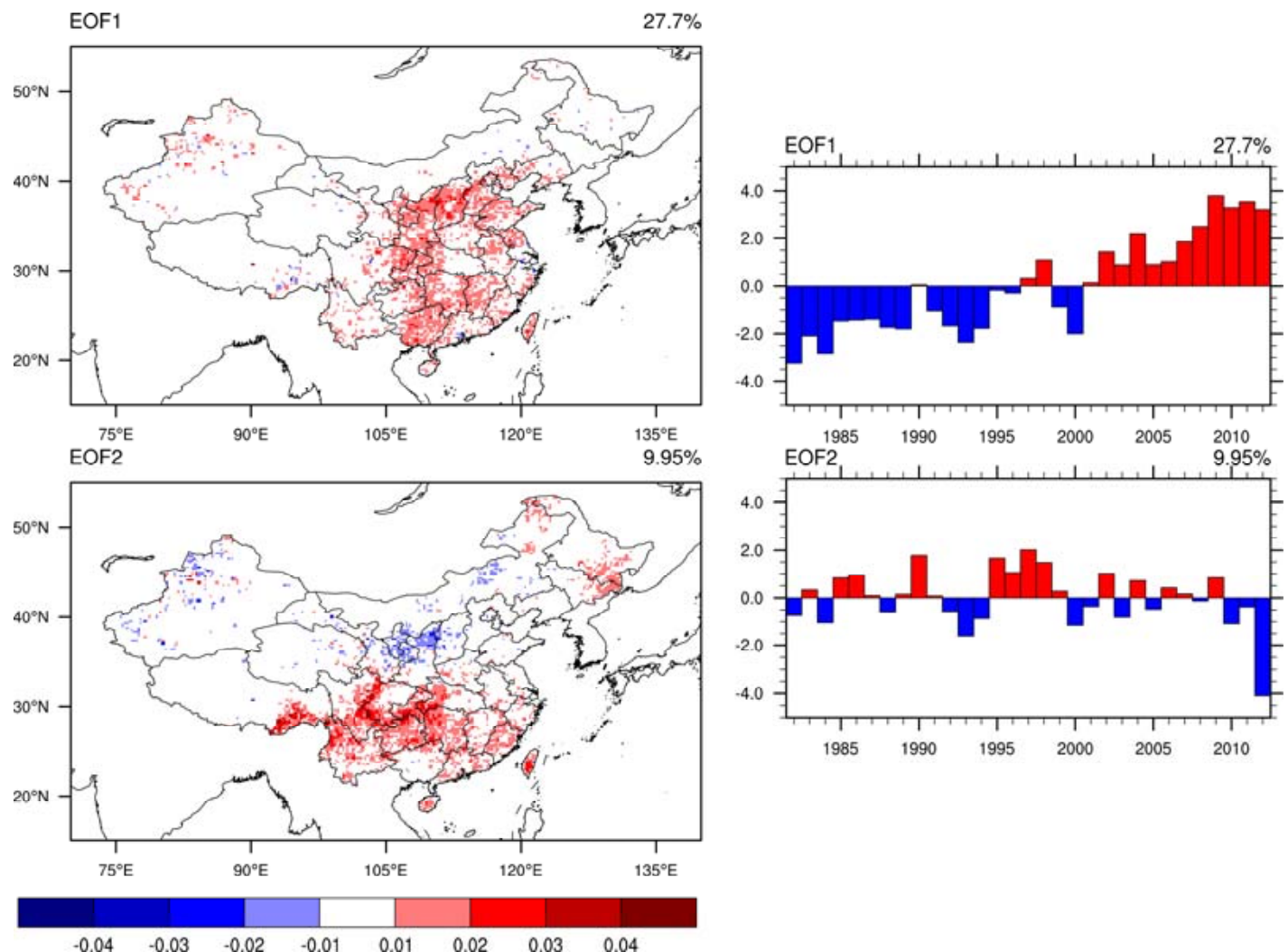

Figure 4. First two leading eigenvectors and associated principal components obtained from the Empirical Orthogonal Function (EOF) analysis for 1982-2012.

We further examine the spatiotemporal patterns of NDVI changes over China by conducting an EOF analysis. Figure 4 shows the eigenvectors and associated principal components (PCs) for the first two leading EOF modes. The first EOF mode, which represents $27.7 \%$ of the total variance, shows positive values in southern and central China and part of the North China Plain that are consistent with the NDVI changes shown in Figure 2. The time series of the first PC represents decadal variations and shows an increasing trend since 2000. Peng et al. [27] noted that significant changes in the growing season NDVI occurred in the 1990s and early 2000s over northern China (e.g., Inner Mongolia and North China). We therefore separate the study period into two parts to examine how the vegetation growth differs. After calculating the NDVI trend before 2000 (1982-1999) and from 2000 on (2000-2012), we see large increases in the NDVI after 2000 in the Ningxia Hui Autonomous Region, north of Shaanxi, and Shanxi Provinces, where the trends in NDVI are not pronounced from 1982-1999 (i.e., the Loess Plateau, Figure 2d). The second EOF mode, which explains approximately 
$10 \%$ of the total variance, denotes the reverse spatial patterns in NDVI changes between the southern and northern areas. The time series of the second PC generally has a 1-3 year cycle from 1982 to 2012 and has strong variations in NDVI in the 1990s. Studies have shown that the decrease in the growing season NDVI after the 1990s in the arid and semi-arid regions of northern China could be attributed to climate change, i.e., drought stress strengthened by warming and reduced rainfall $[27,28]$. As the growing season NDVI significantly differs in the 1990s based on the trend and EOF analysis, and the data temporal coverage differs among the different products, our focus will be on the period starting from 1992 onward when most observations are available.

\subsection{Separating NDVI Changes into Climatic and Non-Climatic Effects}

The above NDVI changes are not only influenced by climate variations, but also by human activities such as LUC. Next we quantify the relative contribution of climate and non-climatic effects using MLR. We first examine how climatic variations are linked to the NDVI changes. Figure $5 a-c$ show the regression coefficients of NDVI associated with the three climatic variables. Positive significant relationships between NDVI and temperature are found over most of South China, except for the northwestern and northeastern regions such as Heilongjiang Province, indicating that temperature is the most significant climatic factor contributing to the increased vegetation growth. However, vegetation changes in most semi-arid and arid regions are highly sensitive to changes in precipitation [10]. Figure $5 \mathrm{~b}$ shows that precipitation dominantly controls the variations in NDVI in the growing season over northwestern and northern China. Thus, warming can enhance vegetation growth over temperature-limited ecoregions but has the opposite effect on water-limited semi-arid and arid ecosystems [54]. The NDVI in central China and parts of the Hetao Region and Guangxi has the greatest positive correlation with radiation, but is negatively correlated with radiation in southern China (Figure 5c). These results indicate that the vegetation-climate relationships are highly heterogeneous across China and that the major climatic drivers for the NDVI changes differ by geographical location and vegetation type. It is also noteworthy that for regions in central China (Figure 2) where the greening trend is significant, the relationships between NDVI and climate variables (temperature, precipitation, and radiation) are insignificant, implying limited climatic impacts.

Next we estimate the NDVI trends in association with non-climatic effects using the MLR analysis by removing the climatic effects from the original NDVI time series. The residual NDVI time series is used to estimate the NDVI changes due to the non-climatic effects (Figure 5d). Note that some regions, including central China, North China Plain, and Guangxi Province, show significant positive trends, greater than 0.08 decade $^{-1}$, implying the non-climatic influences.
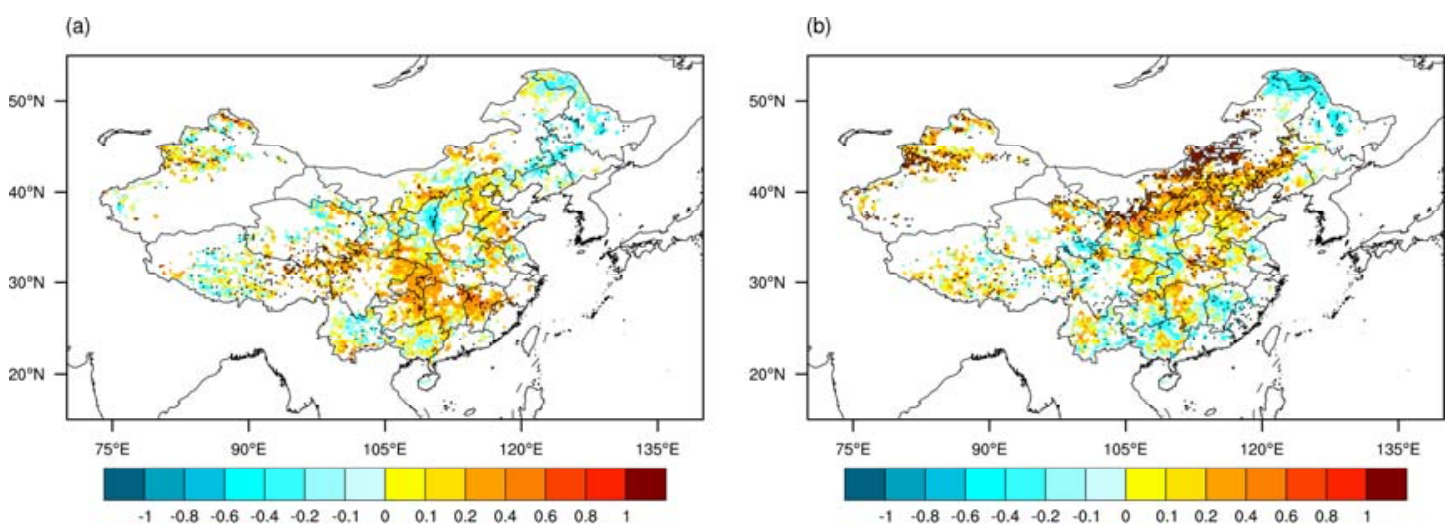

Figure 5. Cont. 
(c)

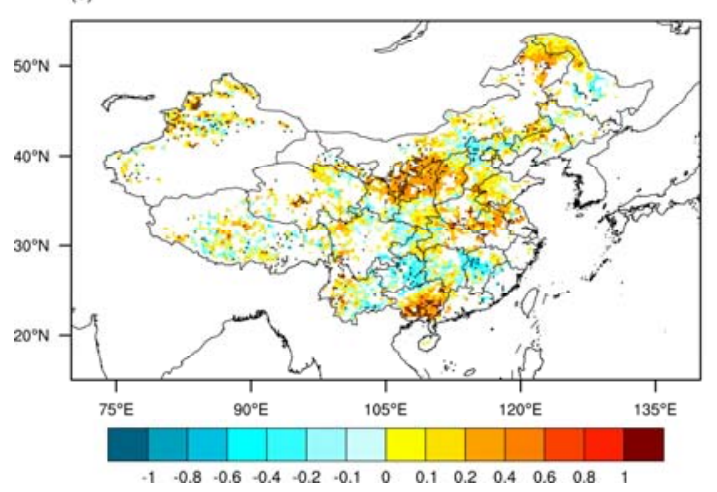

(d)

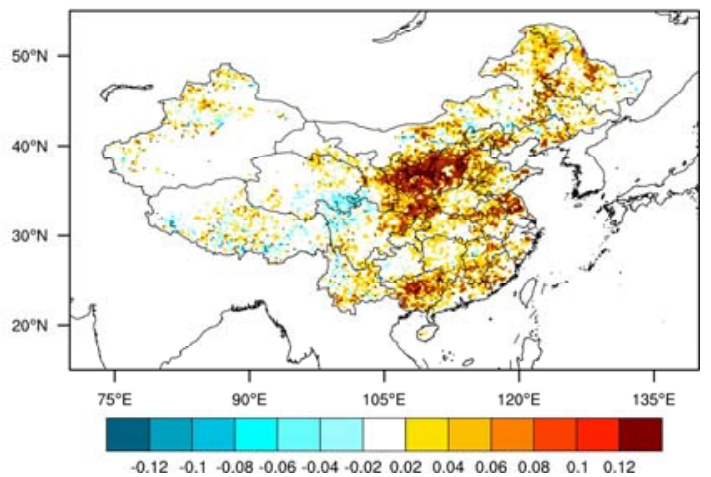

Figure 5. Regression coefficients of NDVI for three climate variables employed in the multiple linear regression (MLR) analysis: (a) temperature; (b) precipitation and (c) radiation; The trends in the residual NDVI time series after removing the climate effects from the original NDVI data via the MLR are shown in (d). The solid black dots denote the regions where the coefficients are statistically significant at the 0.05 level.

\subsection{Linking Non-Climatic Effects on NDVI Changes to LUC}

Previous modeling studies indicated that LUC drives the long-term changes in vegetation greenness $[21,22,55]$. Before quantifying LUC, we first show the main vegetation cover map in China (Figure 6). South China consists primarily of forests, such as mixed forests and evergreen broadleaf and needleleaf forests. Croplands are mostly found in north, northeast China, and Sichuan province, whereas grasslands are in Inner Mongolia, the Hetao region, and the Tibetan Plateau. Comparing with croplands and grasslands, forests basically have more leaves per unit ground surface area and thus higher vegetation index values, particularly in north China (Figure 1a). For simplicity, we combine all forest classes from classes 1 to 5 (referred to as forests), and all classes of grasslands, shrublands, and savannas from classes 6 to 10 (referred to as grasslands), because each group shares similar NDVI values in China (see more discussion of this below).

Figure 7 shows the changes in the fractional cover of forests, croplands, and grasslands for the year 2012 with reference to 1992. Increased forest cover can be seen for many regions in south China. The cropland fractional cover has decreased by up to $50 \%$ for major broadleaf forest areas such as the Guangdong and Guangxi provinces, and some regions in the Guizhou and Sichuan provinces. Some increase in grasslands can be noticed south of $25^{\circ} \mathrm{E}$ and some grasslands are converted to forests in southwestern China. As for North China, the cropland fractional cover has increased in the North China Plain, especially in the Shandong, Hebei, Shannxi, and Shanxi provinces. Large increases in grasslands have occurred over Inner Mongolia and northeast China. The changes in NDVI indicate that vegetation greening is obvious south of $25^{\circ} \mathrm{E}$ which can be attributed to the large percentage of croplands converting to broadleaf forests and grasslands. However, one may find that the land cover changes are large in parts of South China (around $30^{\circ} \mathrm{N}$ ), where the increases in mixed forest cover and the associated changes in grasslands and croplands cannot explain the moderate greening trends (Figures 2 and $5 \mathrm{~d}$ ). In contrast, the land cover conversions can reasonably explain the greening trends in north China, for instance, the cropland cover increases in North China Plain, and the forests that grow in some regions in the Shanxi and Shannxi provinces. A higher percentage of grasslands has also increased along the boundaries between Inner Mongolia and northeast China on the basis of the original grasslands. 


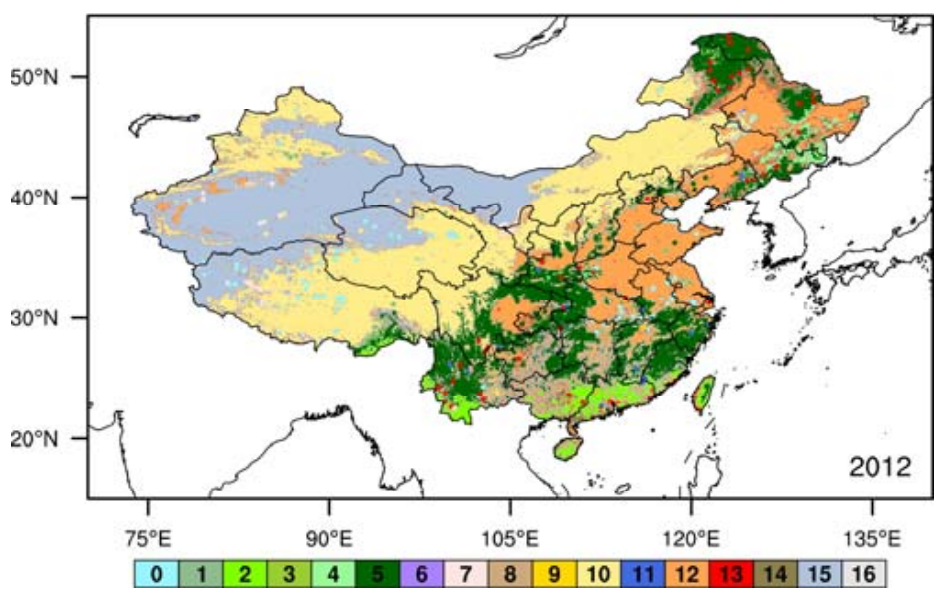

Figure 6. Land cover map in 2012 from the Moderate Resolution Imaging Spectroradiometer (MODIS) product for 17 classes: 0 water; 1 evergreen needleleaf forest; 2 evergreen broadleaf forest; 3 deciduous needleleaf forest; 4 deciduous broadleaf forest; 5 mixed forests; 6 closed shrubland; 7 open shrubland; 8 woody savannas; 9 savannas; 10 grassland; 11 permanent wetland; 12 cropland; 13 urban and built up; 14 cropland natural vegetation mosaic; 15 snow and ice; 16 barren and sparsely vegetated land.
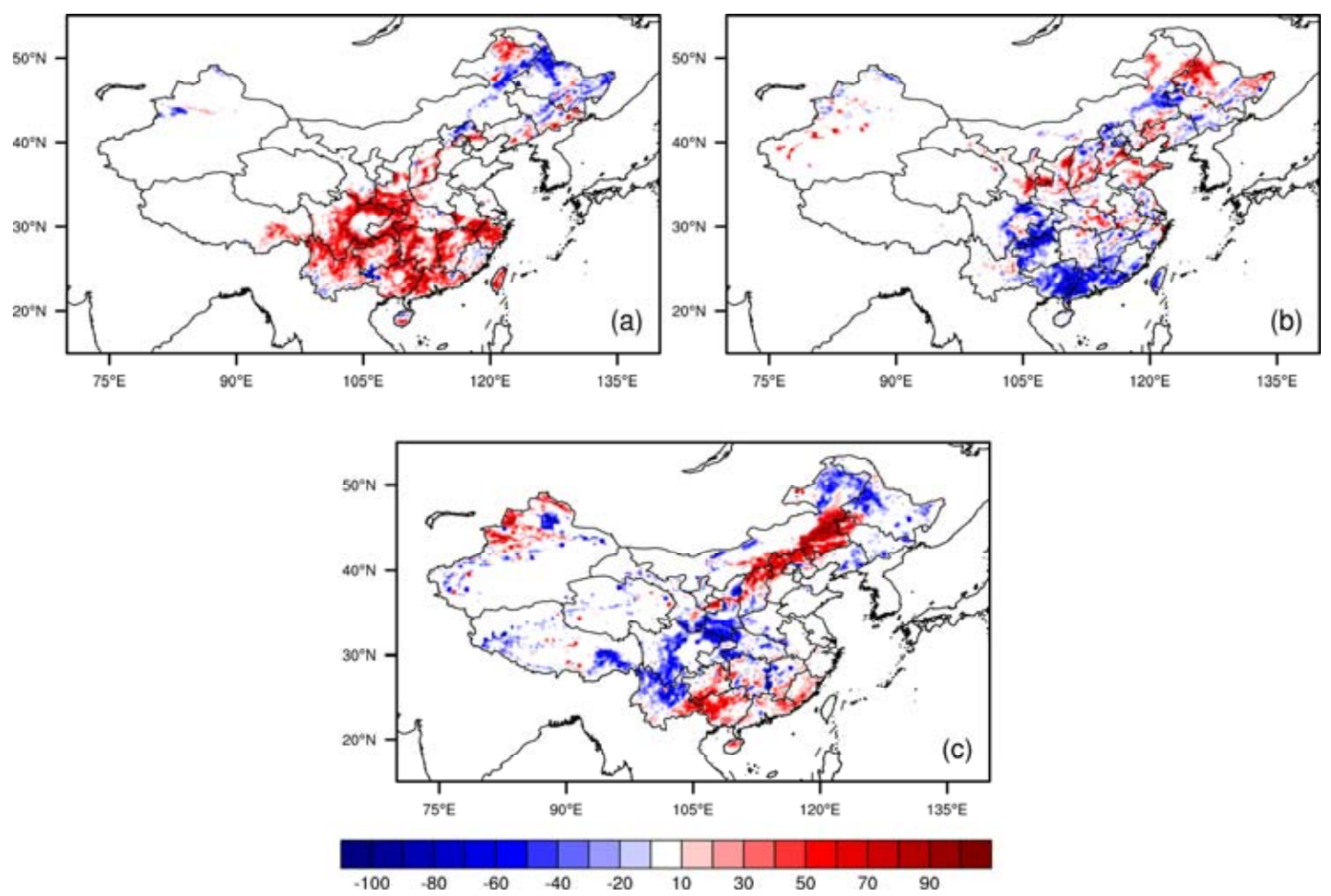

Figure 7. Changes in fractional cover of three main vegetation types (2012 versus 1992), (a) forests; (b) croplands and (c) grasslands. Forests and grasslands are expressed as the sum of classes 1 to 5, and classes 6 to 10, respectively, whereas croplands are class 12 from the International Geosphere-Biosphere Programme (IGBP) land cover legend.

Why is the NDVI in North China more sensitive to LUC than in South China? A possible explanation is that South China is primarily covered by forests and dense grasslands/croplands with similar NDVI values during the growing season, while these two types of vegetation in North China have distinct NDVI values. To confirm this feature, we calculate the climatological NDVI mean values and their range (represented as the 5th and 95th percentiles) for each land cover class in South 
China $\left(25^{\circ} \mathrm{N}-35^{\circ} \mathrm{N}\right)$ and North China $\left(35^{\circ} \mathrm{N}-45^{\circ} \mathrm{N}\right)$ (Table 1). Note that mixed forests consist of tree communities with interspersed mixtures or mosaics of four main forest types (class 1-4). Basically, the four main forest classes and other vegetation types (crop, savannas, and grass) have similar NDVI values during the growing season in South China (Table 1). This explains why the LUC has relatively small impacts on the NDVI variation as the NDVI is insensitive to conversions between forests and the other vegetation types. In contrast, the climatological NDVI values of the three main forest classes differ by $>0.3$ from those of shrublands, grasslands, and croplands in North China, which is covered primarily by crops and grasslands with low NDVI values in the semi-arid regions. So the significant vegetation greening in North China is due to the fractional cover increases in crops, grasslands, and forests in North China Plain and Mongolia.

Table 1. Statistics of NDVI ranges (represented as the 5th and 95th percentiles) and mean values by land cover in South $\left(25^{\circ} \mathrm{N}-35^{\circ} \mathrm{N}\right)$ and North China $\left(35^{\circ} \mathrm{N}-45^{\circ} \mathrm{N}\right)$.

\begin{tabular}{|c|c|c|c|c|c|}
\hline \multirow{2}{*}{ Class Name } & \multicolumn{2}{|c|}{ South China } & \multirow{2}{*}{ Class Name } & \multicolumn{2}{|c|}{ North China } \\
\hline & Range & Mean & & Range & Mean \\
\hline evergreen needleleaf forest & $0.51-0.65$ & 0.58 & evergreen needleleaf forest & $0.36-0.63$ & 0.50 \\
\hline evergreen broadleaf forest & $0.60-0.74$ & 0.69 & deciduous broadleaf forest & $0.57-0.63$ & 0.61 \\
\hline deciduous broadleaf forest & $0.69-0.78$ & 0.74 & mixed forests & $0.49-0.74$ & 0.63 \\
\hline mixed forests & $0.60-0.77$ & 0.70 & closed shrubland & $0.40-0.59$ & 0.50 \\
\hline woody savannas & $0.56-0.72$ & 0.64 & open shrubland & $0.11-0.38$ & 0.17 \\
\hline grassland & $0.33-0.66$ & 0.50 & grassland & $0.16-0.56$ & 0.32 \\
\hline cropland & $0.45-0.67$ & 0.57 & cropland & $0.34-0.58$ & 0.48 \\
\hline
\end{tabular}

\subsection{Verifying Non-Climatic Effects on NDVI Changes with Socioeconomic Data}

If the above LUC effects on NDVI changes are correct, we should be able to use some socioeconomic data derived from the China Statistical Yearbooks to provide independent confirmation at the provincial level. Six regions that exhibit the significant greening trends due to non-climatic effects are chosen for an in-depth analysis. Figure 8 shows the residual NDVI trends at the provincial level from mainland China. Six out of the 31 provincial administrative regions show significant $(p<0.01)$ vegetation greening from 1992 to 2012. The six greening regions are Guangxi, Fujian, Jiangsu, Ningxia, Shaanxi, and Shanxi. Firstly, we calculate the forest coverage change from the two measurements between 1990s and 2010s. The forest percentage changes due to LUC (Figure 7) are comparable to the measurements from the Chinese Statistical Yearbooks (Table 2), although uncertainties exist in Ningxia and Fujian. It is known that ecological conservation and restoration are beneficial for mitigating problems caused by climate change. China has made great efforts in those areas. Afforestation should effectively increase vegetation greenness, particularly in North China. Comparison of the NDVI trends with the accumulation of planted forests (1992-2012) per unit area (10 hectare/hectare) at the provincial level implies that afforestation is a main driving factor for the enhanced vegetation greenness. Among these administrative regions, Shanxi has the largest planted forest areas and thus has relatively stronger non-climatic effects (Table 2). Two of the eight greening regions (Jinagsu and Fujian) have relatively smaller planted forest areas. Based on the China Agricultural Yearbooks, a strong indication of greening was also found in the cropland regions of the North China Plain and north of Jiangsu, which is likely the result of improved crop varieties, cropping practices, and agricultural techniques [56]. 


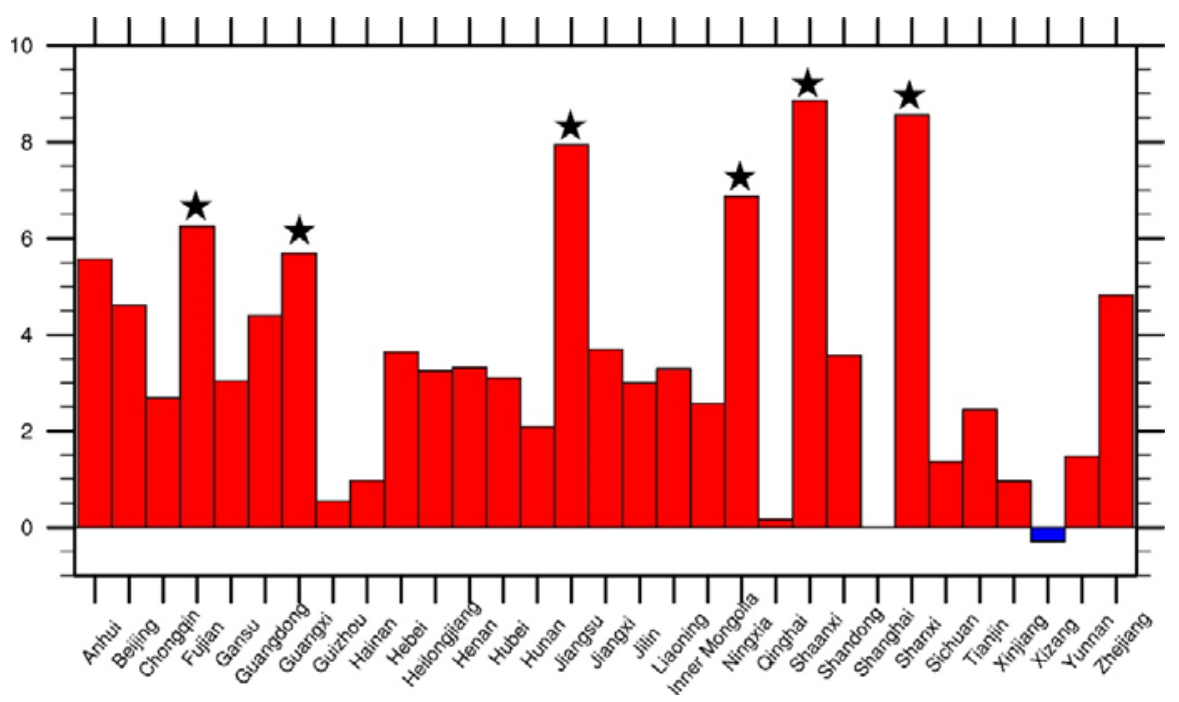

Figure 8. The residual NDVI trends $\left(10^{-2}\right)$ at the provincial scale. The asterisk indicates a statistical significance at the 0.01 level.

Besides afforestation, fire disturbance has been recognized as a major force in vegetation dynamics $[57,58]$. Basically, the decline of fire events favors vegetation growth and vegetation restoration. The differences in fire affected areas between two periods of 1991-2001 and 2002-2012 indicate that the occurrence of fire events has dramatically decreased since the 2000s. Jiangsu experienced a marked decline in fire, which probably partially explains the greening trend. In addition, urbanization, a more extreme case of LUC, has large impacts on vegetation variations, especially in China which has experienced a rapid urban expansion during the past few decades [59], and would have a negative impact on the NDVI. Overall, the estimated NDVI changes due to the non-climatic effects are basically consistent with the satellite-derived LUC and the socioeconomic data at the provincial level linked to afforestation and fire.

Table 2. Differences in forest cover between the period of 1989-1993 and 2009-2013 from the yearbook, changes in forest cover between 1992 and 2012 from the land cover data, accumulated planted forest areas per unit area (10 hectare/ hectare) from 1992 to 2012 at the provincial scale, and differences in the percentage coverage of fires between 1991-2001 and 2002-2012.

\begin{tabular}{cccccc}
\hline Regions & $\begin{array}{c}\text { Forest Cover } \\
\text { Changes from } \\
\text { Yearbook (\%) }\end{array}$ & $\begin{array}{c}\text { Forest Cover } \\
\text { Changes from Land } \\
\text { Cover Data (\%) }\end{array}$ & $\begin{array}{c}\text { Accumulated } \\
\text { Planted Forest (10 } \\
\text { Hectare/Hectare) }\end{array}$ & $\begin{array}{c}\text { Urbanization } \\
\text { (\%) }\end{array}$ & Fire (\%) \\
\hline Shanxi & 9.92 & 10.81 & 4.67 & 0.65 & 0.11 \\
Shaanxi & 17.27 & 25.71 & 3.94 & 0.42 & $-80.33^{*}$ \\
Jiangsu & 11.78 & 3.52 & 1.06 & 3.55 & $-47.48^{*}$ \\
Ningxia & 10.35 & 0.16 & 2.71 & 0.60 & -42.49 \\
Guangxi & 31.17 & 30.37 & 1.91 & 0.46 & -21.84 \\
Fujian & 15.35 & 4.69 & 0.87 & 0.98 & 10.68 \\
\hline
\end{tabular}

Note: Values with “*” are statistically significant at the 0.1 level.

\section{Uncertainties in the Attribution of Observed NDVI Changes}

In this study, we explore the possible relative contributions of vegetation greening in China due to climatic and human influences from multiple observational datasets (e.g., the satellite-based vegetation dataset together with relevant climate, land cover, and socioeconomic data). For the 31 years of the period, overall there is a long-term large-scale greening trend in China during the growing season. However, it is also expected to see some short-term greening/browning variations associated with short-term climate disturbances (e.g., ENSO events) and human factors (e.g., afforestation) during this 
period, particularly at the local and regional scales. As stated previously, our study is mainly focused on the large-scale long-term NDVI trends, instead of the short-term NDVI variability.

There are some limitations and uncertainties in attributing the observed vegetation changes. First, climate change, particularly global warming, is at least partly caused by human activities [60]. The largest contribution comes from the release of $\mathrm{CO}_{2}$ gas to the atmosphere. A warmer climate could contribute to the greenness in vegetation. Given the strong connections between climate and human activities, these driving factors cannot be considered in isolation. For example, the relative contribution of human induced warming and the climate change warming needs to be further explored. Second, the effects of climate factors on vegetation variations are still under debate due to vegetation's non-linear responses to climate change and the spatiotemporal variations of such responses $[17,23,61]$. We have not quantitatively considered the effects of the vegetation response time. As is known, vegetation is sensitive to climate factors and has a response time on the order of months. Wu et al. [61] showed that climatic indicators can better explain vegetation growth when the time-lag effects are considered. Lü et al. [25] proposed that climate may significantly influence vegetation on decadal time scales. The vegetation-climate interactions are highly heterogeneous and thus need further investigation. Third, there are other studies showing that both climatic factors and human activities have contributions to the regional greening trends over China in the recent decades. For example, rising atmospheric $\mathrm{CO}_{2}$ concentration and nitrogen $(\mathrm{N})$ deposition can all contribute significantly to the vegetation greenness $[21,22,55]$. However, it is very difficult to provide the direct linkage from these non-climatic processes to vegetation variations using observations. Ecological modelling suggested that LUC plays a more significant role in vegetation greenness in China [21,22]. Liu and Lei [62] indicated that NDVI variations in China are affected by external factors such as drought and afforestation. Liu et al. [63] showed a strong correlation between the cumulative afforestation area and NDVI during the period from 2001-2012. Zhu et al. [64] demonstrated in a case study on Guangzhou, China, that land cover change plays an important role in determining the greenness trend as well, particularly at local scales. Increases in irrigation, grassland restoration, and conservation, and agricultural production in Inner Mongolia may have also contributed to the NDVI greening in these farmlands [65,66]. Jiang et al. [67] confirmed based on an analysis of the fractional vegetation coverage (FVC) in Beijing, China, that human activities have large impacts on the FVC change and some socioeconomic influences (e.g., population growth, gross domestic product) on the FVC are highly spatially heterogeneous. Population pressure could cause vegetation browning, especially in developing countries, whereas economic and agriculture vitality could potentially exert significant positive effects on vegetation greening (see for example, [25]). Thus, vegetation responses to various climate and human factors require further analysis [55]. Fourth, the present study uses the socioeconomic data at the provincial level, which may influence its reliability of the data accuracy. For example, the forest cover change in the Ningxia and Fujian provinces has relatively larger differences between the satellite-based and socioeconomic data. Therefore, the use of the provincial level socioeconomic data needs caution [25]. Furthermore, the MLR analysis used to separate the climatic and non-climatic effects on NDVI may have underestimated the climatic impacts [11,17]. Applying other approaches to quantify the relative contributions of observed vegetation greening is needed in the future.

\section{Conclusions}

The present study demonstrates that a statistically significant positive NDVI trend during the growing season (April-October) for the period from 1982-2012 is found in more than 34\% of the study regions, mainly in central and North China, whereas significant decreases in NDVI are only seen in less than $5 \%$ of the areas. The growing season NDVI shows significant changes during the late 1990s in northern China via the EOF and trend analyses. The relationship between NDVI and temperature is positive, especially in southern China, which implies that warmer climate could enhance vegetation activity. Precipitation is a primary factor that controls the variations in NDVI over water-limited 
regions (e.g., northwestern and northern China). NDVI has the greatest positive correlation with radiation in central China and the Guangxi province. These results indicate that the relationships between vegetation and climate factors highly differ by geographical locations and vegetation types.

By removing the climatic effects from the original NDVI by using the MLR analysis, we estimate the NDVI changes in association with the non-climatic effects. Land use change (LUC) is one of the most important factors driving the long-term changes in vegetation greenness. The croplands increase in the North China Plain, whereas forests grow in some regions in the Shanxi and Shaanxi provinces. A higher percentage of grasslands also increase in northeast China. Therefore, the significant vegetation greening is due to the increase in crops, grasslands, and forests in the North China Plain and Mongolia. However, changes in land cover are large in parts of South China (around $30^{\circ} \mathrm{N}$ ), where the increase in mixed forest cover and associated changes in grasslands and croplands cannot explain the NDVI variations. A possible explanation is that South China is primarily covered by forests and dense grasslands/croplands with similar NDVI values. Thus, the NDVI is insensitive to conversions between forests and the other types in South China.

We also use some socioeconomic data as independent sources to attribute the human influences on vegetation variations at the provincial level. Six out of the 31 provincial administrative regions have experienced significant vegetation greening. The accumulated planted forests in the socioeconomic data imply that afforestation drives the increased vegetation greenness. Overall, it is challenging to detect and attribute the regional vegetation greening signal due to the lack of long-term observational records and uncertainties and deficiencies in satellite data and model simulations. Nevertheless, this study provides a basis for quantifying the non-climatic effects due to possible human influences on vegetation greening in China.

Acknowledgments: This work was jointly supported by the National Natural Science Foundation of China (41605034, 41625019, 41605042), the Natural Science Foundation for Higher Education Institutions in Jiangsu Province (16KJB170007), the National Natural Science Foundation of Jiangsu Province (BK20160948, BK20151525), the National Key Research and Development Program of China (2016YFA0600702), and the Startup Foundation for Introducing Talent of Nanjing University of Information Science \& Technology (2014r001), as well as the Priority Academic Program Development of Jiangsu Higher Education Institutions (PAPD).

Author Contributions: W.H., and L.Z. contributed the central idea, analyzed most of the data, and wrote the initial draft of the paper. The remaining authors contributed to refining the ideas, carrying out additional analyses, and finalizing this paper.

Conflicts of Interest: The authors declare no conflict of interest.

\section{References}

1. Zhou, L.; Tucker, C.J.; Kaufmann, R.K.; Slayback, D.; Shabanov, N.V.; Myneni, R.B. Variations in northern vegetation activity inferred from satellite data of vegetation index during 1981 to 1999. J. Geophys. Res. 2001, 106, 20069-20083. [CrossRef]

2. Zhou, L.; Kaufmann, R.K.; Tian, Y.; Myneni, R.B.; Tucker, C.J. Relation between interannual variations in satellite measures of northern forest greenness and climate between 1982 and 1999. J. Geophys. Res. 2003, 108, 4004. [CrossRef]

3. Piao, S.; Wang, X.; Ciais, P.; Zhu, B.; Wang, T.A.O.; Liu, J.I. E. Changes in satellite-derived vegetation growth trend in temperate and boreal Eurasia from 1982 to 2006. Glob. Chang. Biol. 2011, 17, 3228-3239. [CrossRef]

4. Myneni, R.B.; Keeling, C.D.; Tucker, C.J.; Asrar, G.; Nemani, R.R. Increased plant growth in the northern high latitudes from 1981 to 1991. Nature 1997, 386, 698-702. [CrossRef]

5. Zhou, L.; Dickinson, R.E.; Tian, Y.; Zeng, X.; Dai, Y.; Yang, Z.L.; Schaaf, C.B.; Gao, F.; Jin, Y.; Strahler, A.; et al. Comparison of seasonal and spatial variations of albedos from Moderate-Resolution Imaging Spectroradiometer (MODIS) and Common Land Model. J. Geophys. Res. 2003, 108, 4488. [CrossRef]

6. Hua, W.; Chen, H. Impacts of regional-scale land use/land cover change on diurnal temperature range. Adv. Clim. Chang. Res. 2013, 4, 166-172.

7. Bonan, G.B. Forests and climate change: Forcings, feedbacks, and the climate benefits of forests. Science 2008, 320, 1444-1449. [CrossRef] [PubMed] 
8. Lee, X.; Goulden, M.L.; Hollinger, D.Y.; Barr, A.; Black, T.A.; Bohrer, G.; Bracho, R.; Drake, B.; Goldstein, A.; $\mathrm{Gu}$, L.; et al. Observed increase in local cooling effect of deforestation at higher latitudes. Nature 2011, 479, 384-387. [CrossRef] [PubMed]

9. Peng, S.; Piao, S.; Zeng, Z.; Ciais, P.; Zhou, L.; Li, L.Z.X.; Myneni, R.B.; Yin, Y.; Zeng, H. Afforestation in China cools local land surface temperature. Proc. Natl. Acad. Sci. 2014, 111, 2915-2919. [CrossRef] [PubMed]

10. Nemani, R.R.; Keeling, C.D.; Hashimoto, H.; Jolly, W.M.; Piper, S.C.; Tucker, C.J.; Myneni, R.B.; Running, S.W. Climate-driven increases in global terrestrial net primary production from 1982 to 1999. Science 2003, 300, 1560-1563. [CrossRef] [PubMed]

11. Gong, D.Y.; Ho, C.H. Detection of large-scale climate signals in spring vegetation index (normalized difference vegetation index) over the Northern Hemisphere. J. Geophys. Res. 2003, 108, 4498. [CrossRef]

12. Park, H.S.; Sohn, B.J. Recent trends in changes of vegetation over East Asia coupled with temperature and rainfall variations. J. Geophys. Res. 2010, 115, D14101. [CrossRef]

13. Zhao, M.; Running, S.W. Drought-induced reduction in global terrestrial net primary production from 2000 through 2009. Science 2010, 329, 940-943. [CrossRef] [PubMed]

14. Xu, L.; Myneni, R.B.; Chapin Iii, F.S.; Callaghan, T.V.; Pinzon, J.E.; Tucker, C.J.; Zhu, Z.; Bi, J.; Ciais, P.; Tommervik, H.; et al. Temperature and vegetation seasonality diminishment over northern lands. Nat. Clim. Chang. 2013, 3, 581-586. [CrossRef]

15. Wang, X.; Piao, S.; Ciais, P.; Li, J.; Friedlingstein, P.; Koven, C.; Chen, A. Spring temperature change and its implication in the change of vegetation growth in North America from 1982 to 2006. Proc. Natl. Acad. Sci. USA 2011, 108, 1240-1245. [CrossRef] [PubMed]

16. Piao, S.; Fang, J.; Zhou, L.; Ciais, P.; Zhu, B. Variations in satellite-derived phenology in China's temperate vegetation. Glob. Chang. Biol. 2006, 12, 672-685. [CrossRef]

17. De Jong, R.; Schaepman, M.E.; Furrer, R.; de Bruin, S.; Verburg, P.H. Spatial relationship between climatologies and changes in global vegetation activity. Glob. Chang. Biol. 2013, 19, 1953-1964. [CrossRef] [PubMed]

18. Hua, W.; Chen, H. Recognition of climatic effects of land use/land cover change under global warming. Chin. Sci. Bull. 2013, 58, 3852-3858. [CrossRef]

19. Hua, W.; Chen, H.; Sun, S.; Zhou, L. Assessing climatic impacts of future land use and land cover change projected with the CanESM2 model. Int. J. Climatol. 2015, 35, 3661-3675. [CrossRef]

20. Hua, W.; Chen, H.; Li, X. Effects of future land use change on the regional climate in China. Sci. China Earth Sci. 2015, 58, 1840-1848. [CrossRef]

21. Piao, S.; Yin, G.; Tan, J.; Cheng, L.; Huang, M.; Li, Y.; Liu, R.; Mao, J.; Myneni, R.B.; Peng, S.; et al. Detection and attribution of vegetation greening trend in China over the last 30 years. Glob. Chang. Biol. 2015, 21, 1601-1609. [CrossRef] [PubMed]

22. Zhu, Z.; Piao, S.; Myneni, R.B.; Huang, M.; Zeng, Z.; Canadell, J.G.; Ciais, P.; Sitch, S.; Friedlingstein, P.; Arneth, A.; et al. Greening of the Earth and its drivers. Nat. Clim. Chang. 2016, 6, 791-795. [CrossRef]

23. Piao, S.; Nan, H.; Huntingford, C.; Ciais, P.; Friedlingstein, P.; Sitch, S.; Peng, S.; Ahlström, A.; Canadell, J.G.; Cong, N.; et al. Evidence for a weakening relationship between interannual temperature variability and northern vegetation activity. Nat. Commun. 2014, 5. [CrossRef] [PubMed]

24. State Forestry Administration of the People's Republic of China, B. Eighth National Forest Resource Inventory Report (2009-2013); State Forestry Administration of the People's Republic of China: Beijing, China, 2014.

25. Lü, Y.; Zhang, L.; Feng, X.; Zeng, Y.; Fu, B.; Yao, X.; Li, J.; Wu, B. Recent ecological transitions in China: Greening, browning, and influential factors. Sci. Rep. 2015, 5, 8732. [CrossRef] [PubMed]

26. Piao, S.; Fang, J.; Zhou, L.; Guo, Q.; Henderson, M.; Ji, W.; Li, Y.; Tao, S. Interannual variations of monthly and seasonal normalized difference vegetation index (NDVI) in China from 1982 to 1999. J. Geophys. Res. 2003, 108, 4401. [CrossRef]

27. Peng, S.; Chen, A.; Xu, L.; Cao, C.; Fang, J.; Myneni, R.B.; Pinzon, J.E.; Tucker, C.J.; Piao, S. Recent change of vegetation growth trend in China. Environ. Res. Lett. 2011, 6, 044027. [CrossRef]

28. Xu, X.; Piao, S.; Wang, X.; Chen, A.; Ciais, P.; Myneni, R.B. Spatio-temporal patterns of the area experiencing negative vegetation growth anomalies in China over the last three decades. Environ. Res. Lett. 2012, 7, 035701. [CrossRef]

29. Anav, A.; Murray-Tortarolo, G.; Friedlingstein, P.; Sitch, S.; Piao, S.; Zhu, Z. Evaluation of land surface models in reproducing satellite Derived leaf area index over the high-latitude northern hemisphere. Part II: Earth system models. Remote Sens. 2013, 5, 3637-3661. [CrossRef] 
30. Murray-Tortarolo, G.; Anav, A.; Friedlingstein, P.; Sitch, S.; Piao, S.; Zhu, Z.; Poulter, B.; Zaehle, S.; Ahlström, A.; Lomas, M.; et al. Evaluation of land surface models in reproducing satellite-derived LAI over the high-latitude Northern Hemisphere. Part I: Uncoupled DGVMs. Remote Sens. 2013, 5, 4819-4838. [CrossRef]

31. Fang, H.; Jiang, C.; Li, W.; Wei, S.; Baret, F.; Chen, J.M.; Garcia-Haro, J.; Liang, S.; Liu, R.; Myneni, R.B.; et al. Characterization and intercomparison of global moderate resolution leaf area index (LAI) products: Analysis of climatologies and theoretical uncertainties. J. Geophys. Res. 2013, 118. [CrossRef]

32. Tucker, C.J.; Pinzon, J.E.; Brown, M.E.; Slayback, D.A.; Pak, E.W.; Mahoney, R.; Vermote, E.F.; Saleous, N.E. An extended AVHRR 8-km NDVI dataset compatible with MODIS and SPOT vegetation NDVI data. Int. J. Remote Sens. 2015, 26, 4485-4498. [CrossRef]

33. Beck, H.E.; McVicar, T.R.; van Dijk, A.I.J.M.; Schellekens, J.; de Jeu, R.A.M.; Bruijnzeel, L.A. Global evaluation of four AVHRR-NDVI data sets: Intercomparison and assessment against Landsat imagery. Remote Sens. Environ. 2011, 115, 2547-2563. [CrossRef]

34. Fensholt, R.; Proud, S.R. Evaluation of Earth Observation based global long term vegetation trends-Comparing GIMMS and MODIS global NDVI time series. Remote Sens. Environ. 2012, 119, 131-147. [CrossRef]

35. Zeng, F.W.; Collatz, G.; Pinzon, J.; Ivanoff, A. Evaluating and quantifying the climate-driven interannual variability in global inventory modeling and mapping studies (GIMMS) normalized difference vegetation index (NDVI3g) at global scales. Remote Sens. 2013, 5, 3918-3950. [CrossRef]

36. Loveland, T.; Brown, J.; Ohlen, D.; Reed, B.; Zhu, Z.; Yang, L.; Howard, S. ISLSCP II IGBP DISCover and SiB Land Cover, 1992-1993. In Hall, ISLSCP Initiative II Collection. Data Set; Forrest, G., Collatz, G., Meeson, B., Los, S., de Colstoun, E.B., Landis, D., Eds.; Oak Ridge National Laboratory Distributed Active Archive Center: Oak Ridge, Tennessee, TN, USA, 2009.

37. Friedl, M.A.; Sulla-Menashe, D.; Tan, B.; Schneider, A.; Ramankutty, N.; Sibley, A.; Huang, X. MODIS Collection 5 global land cover: Algorithm refinements and characterization of new datasets. Remote Sens. Environ. 2010, 114, 168-182. [CrossRef]

38. Wu, J.; Gao, X. A gridded daily observation dataset over China region and comparison with the other datasets. Chin. J. Geophys. 2013, 56, 1102-1111.

39. Kalnay, E.; Kanamitsu, M.; Kistler, R.; Collins, W.; Deaven, D.; Gandin, L.; Iredell, M.; Saha, S.; White, G.; Woollen, J.; et al. The NCEP/NCAR 40-year reanalysis project. Bull. Amer. Meteor. Soc. 1996, 77, 437-471. [CrossRef]

40. Harris, I.; Jones, P.D.; Osborn, T.J.; Lister, D.H. Updated high-resolution grids of monthly climatic observations-the CRU TS3. 10 Dataset. Int. J. Climatol. 2014, 34, 623-642. [CrossRef]

41. Wen, Q.H.; Zhang, X.; Xu, Y.; Wang, B. Detecting human influence on extreme temperatures in China. Geophys. Res. Lett. 2013, 40, 1171-1176. [CrossRef]

42. Peng, S.; Piao, S.; Ciais, P.; Myneni, R.B.; Chen, A.; Chevallier, F.; Dolman, A.J.; Janssens, I.A.; Penuelas, J.; Zhang, G.; et al. Asymmetric effects of daytime and night-time warming on Northern Hemisphere vegetation. Nature 2013, 501, 88-92. [CrossRef] [PubMed]

43. Holben, B.N. Characteristics of Maximum Value Composite images from temporal AVHRR data. Int. J. Remote Sens. 1986, 7, 1417-1434. [CrossRef]

44. Sen, P.K. Estimates of the regression coefficient based on Kendall's tau. J. Am. Stat. Assoc. 1968, 63, 1379-1389. [CrossRef]

45. Richard, O.G. Statistical Methods for Environmental Pollution Monitoring; John Wiley \& Sons: New York, NY, USA, 1987.

46. Davis, J.C. Statistics and Data Analysis in Geology, 2nd ed.; John Wiley and Sons: New York, NY, USA, 1986; pp. 524-537.

47. Running, S.W.; Nemani, R.R.; Heinsch, F.A.; Zhao, M.; Reeves, M.; Hashimoto, H. A continuous satellite-derived measure of global terrestrial primary production. BioScience 2004, 54, 547-560. [CrossRef]

48. Tung, K.K.; Zhou, J. The Pacific's response to surface heating in 130 yr of SST: La Niña-like or El Niño-like? J. Atmos. Sci. 2010, 67, 2649-2657. [CrossRef]

49. Durbin, J.; Watson, G.S. Testing for serial correlation in least squares regression, III. Biometrika 1971, 58, 1-19. [CrossRef] 
50. Grekousis, G.; Mountrakis, G.; Kavouras, M. An overview of 21 global and 43 regional land-cover mapping products. Int. J. Remote Sens. 2015, 36, 5309-5335. [CrossRef]

51. Hansen, M.C.; Reed, B. A comparison of the IGBP DISCover and University of Maryland $1 \mathrm{~km}$ global land cover products. Int. J. Remote Sens. 2000, 21, 1365-1373. [CrossRef]

52. Friedl, M.A.; McIver, D.K.; Hodges, J.C.F.; Zhang, X.Y.; Muchoney, D.; Strahler, A.H.; Woodcock, C.E.; Gopal, S.; Schneider, A.; Cooper, A.; et al. Global land cover mapping from MODIS: Algorithms and early results. Remote Sens. Environ. 2002, 83, 287-302. [CrossRef]

53. Latifovic, R.; Olthof, I. Accuracy assessment using sub-pixel fractional error matrices of global land cover products derived from satellite data. Remote Sens. Environ. 2004, 90, 153-165. [CrossRef]

54. Zhao, X.; Hu, H.; Shen, H.; Zhou, D.; Zhou, L.; Myneni, R.; Fang, J. Satellite-indicated long-term vegetation changes and their drivers on the Mongolian Plateau. Landsc. Ecol. 2015, 30, 1599-1611. [CrossRef]

55. Mao, J.; Ribes, A.; Yan, B.; Shi, X.; Thornton, P.E.; Seferian, R.; Ciais, P.; Myneni, R.B.; Douville, H.; Piao, S.; et al. Human-induced greening of the northern extratropical land surface. Nat. Clim. Chang. 2016, 6, 959-963. [CrossRef]

56. Liu, Y.; Wang, E.; Yang, X.; Wang, J. Contributions of climatic and crop varietal changes to crop production in the North China Plain, since 1980s. Glob. Chang. Biol. 2010, 16, 2287-2299. [CrossRef]

57. Goetz, S.J.; Bunn, A.G.; Fiske, G.J.; Houghton, R.A. Satellite-observed photosynthetic trends across boreal North America associated with climate and fire disturbance. Proc. Natl. Acad. Sci. 2005, 102, 13521-13525. [CrossRef] [PubMed]

58. Bond-Lamberty, B.; Peckham, S.D.; Ahl, D.E.; Gower, S.T. Fire as the dominant driver of central Canadian boreal forest carbon balance. Nature 2007, 450, 89-92. [CrossRef] [PubMed]

59. Zhou, L.; Dickinson, R.E.; Tian, Y.; Fang, J.; Li, Q.; Kaufmann, R.K.; Tucker, C.J.; Myneni, R.B. Evidence for a significant urbanization effect on climate in China. Proc. Natl. Acad. Sci. 2004, 101, 9540-9544. [CrossRef] [PubMed]

60. IPCC. Climate change 2013: The physical science basis, the contribution of Working Group I to the Fifth Assessment Report of the Intergovernmental Panel on Climate Change; Cambridge University Press: Cambridge, UK, 2013; ISBN: 978-1-107-05799-1.

61. Wu, D.; Zhao, X.; Liang, S.; Zhou, T.; Huang, K.; Tang, B.; Zhao, W. Time-lag effects of global vegetation responses to climate change. Glob. Chang. Biol. 2015, 21, 3520-3531. [CrossRef] [PubMed]

62. Liu, Y.; Lei, H. Responses of natural vegetation dynamics to climate drivers in China from 1982 to 2011. Remote Sens. 2015, 7, 10243-10268. [CrossRef]

63. Liu, X.; Zhu, X.; Li, S.; Liu, Y.; Pan, Y. Changes in growing season vegetation and their associated driving forces in China during 2001-2012. Remote Sens. 2015, 7, 15517-15535. [CrossRef]

64. Zhu, Z.; Fu, Y.; Woodcock, C.E.; Olofsson, P.; Vogelmann, J.E.; Holden, C.; Wang, M.; Dai, S.; Yu, Y. Including land cover change in analysis of greenness trends using all available Landsat 5,7 , and 8 images: A case study from Guangzhou, China (2000-2014). Remote Sens. Environ. 2016, 185, 243-257. [CrossRef]

65. Xin, Z.; Xu, J.; Zheng, W. Spatiotemporal variations of vegetation cover on the Chinese Loess Plateau (1981-2006): Impacts of climate changes and human activities. Sci. China Ser. D-Earth Sci. 2008, 51, 67-78. [CrossRef]

66. Liu, J.; Kuang, W.; Zhang, Z.; Xu, X.; Qin, Y.; Ning, J.; Zhou, W.; Zhang, S.; Li, R.; Yan, C.; et al. Spatiotemporal characteristics, patterns, and causes of land-use changes in China since the late 1980s. J. Geogr. Sci. 2014, 24, 195-210. [CrossRef]

67. Jiang, M.; Tian, S.; Zheng, Z.; Zhan, Q.; He, Y. Human Aactivity influences on vegetation cover changes in Beijing, China, from 2000 to 2015. Remote Sens. 2017. [CrossRef]

(c) 2017 by the authors. Licensee MDPI, Basel, Switzerland. This article is an open access article distributed under the terms and conditions of the Creative Commons Attribution (CC BY) license (http:/ / creativecommons.org/licenses/by/4.0/). 